\title{
Important Role of Caregiver in Management of Systemic Lupus Erythematosus on Patient with Mental Retardation
}

\author{
Dwi Ariani 1,*, Yuniardini Septorini Wimardhani ${ }^{2,3 .}$ \\ 1. Oral Medicine Residency Program, Department of Oral Medicine, Faculty of Dentistry, Universitas \\ Indonesia, Jl. Salemba Raya No.4, Jakarta, 10430, Indonesia \\ 2. Department of Oral Medicine, Faculty of Dentistry, Universitas Indonesia, Jl. Salemba Raya No.4, \\ Jakarta, 10430, Indonesia \\ 3. Cluster of Clinical and Epidemiology and Clinical Studies in Dentistry, Faculty of Dentistry, Universitas \\ Indonesia, Jl. Salemba Raya No.4, Jakarta, 10430, Indonesia \\ *E-mail: drg.ariani@gmail.com
}

\begin{abstract}
Background: Systemic Lupus Erythematous (SLE) is a chronic autoimmune disease causing inflammation, pain and tissue damages. The systemic steroid and antimalarial agents are SLE's standard therapies. The challenges in achieving significant result include the extended period of treatment. Therefore, the patients' compliance to the dentist's treatment is crucial. There are some conditions where patient's compliance is difficult to obtain, for example in patients with mental retardation. To be able to receive information and treatment well, it takes an important role of caregiver to communicate and to assist the daily care.

Objective: To give an overview of management challenges of a case of SLE in a patient with mental retardation in which requires good cooperation with the caregiver to obtain optimal results.

Case report and management: A 22-year-old female patient with mental retardation with her caregiver, counseled from the Department of Dermatology and Venereology of Cipto Mangunkusumo Hospital (RSCM) with a working diagnosis of Bullous Systemic Lupus Erythematous. She had been on three years' treatment for blisters all over her body. Condition improvement of the skin had occurred a week before the visit, accompanied by a history of canker sores on her lips and mouth for three days. Clinical features on lips and mouth showed the oral manifestations of bullous SLE. Topical corticosteroids, alternately with saline, as well as clobetasol propionate $0.05 \%$ cream for topical treatment in lips, have given for therapies. The caregiver has been educated to help the patient for maintaining her oral hygiene and using her drugs on a regular basis. Improving the teeth and mouth condition and patient compliance levels seen in control visits.
\end{abstract}

Conclusion: Effective communication, information, and education to the caregiver are critical in the management of SLE patient with mental retardation. Establishment of trust and equality goals of care is necessary to overcome the limitations of communication and patient compliance in this case.

Keywords: bullous systemic lupus erythematous, caregiver, mental retardation

\section{Introduction}

Systemic Lupus Erythematosus (SLE) is a chronic autoimmune disease that can involve any organ system with a wide range of disease manifestations, and can lead to significant morbidity and even relatively high mortality rate in the first few years after disease diagnosis. SLE is a lifelong disease, characterized by periods of flare and remission. The hallmark of SLE is the malar, or butterfly rash. The rash often extends over the nasal bridge, affects the chin and ears, but spares the nasolabial folds. More than a third of patients has photosensitive, and exacerbation of the photosensitive rash frequently heralds the onset of a systemic flare. ${ }^{1,2}$ SLE is regarded as a complex disease with an etiology that appears to be the interplay of environmental, hormonal, and genetic factors. The strongest risk factor for SLE is clearly gender, more frequent among women than men and most often strikes reproductive-age women. ${ }^{3}$

Patients with chronic disease not only need care from health professionals but also, they frequently require help and support from caregivers (CG). A CG is usually the patient's spouse or significant other, but may also be an adult child, a parent, a friend or another family member. They may help coordinate and get health care for the 
patient, as well as take care of household responsibilities such as chores and finances. 4

\section{Objective}

The objective of this case report was to give an overview of management challenges of SLE patient with mental retardation who requires good cooperation with caregiver to obtain optimal results.

\section{Case Report and Management}

A 22-year-old female who came with her sister as caregiver counseled from the Department of Dermatology and Venereology of RSCM with a working diagnosis of Bullous Systemic Lupus Erythematous. She has been diagnosed moderate mental retardation and depression disorder by the Department of Psychiatry almost a year ago. Alloanamnesis said by her caregiver (CG) that she had been on three years treatment for blisters all over her body. Condition improvement of the skin had occurred a week before the visit. She was complaining of canker sores on her lips and mouth for about one week. It made her difficult to open mouth widely. Two years ago, she visited another dentist at a private dental clinic because of same complaint, had been given chlorhexidine gluconate $0.2 \%$ mouthwash, but she didn't well cooperated and never got to another visit. She had been on corticosteroid treatment for three years, using Methylprednisolone. It had been tapering down to minimal doses. She already finished her treatment two weeks ago and continued her medication with antimalarial, using $250 \mathrm{mg}$ Chloroquine once a day for a week, Vitamin D3 $500 \mathrm{mg}$ once a day, and sunblock for her skin. She used natural honey for moistening her lips.

She was only smiling and looking up her CG when she has been asked about her medical history. She spoke only simple words, but is conceived as quiet one. She couldn't express her feeling or pain. She didn't react to long questions but she could be done the simple order, such as opened her mouth for oral examination, looked right or left for taking dental pictures. The patient was jobless and didn't finish her elementary school. She moved up to her sister one year ago because she had been neglected by her step mother and biological father. On her daily, she can't take care of herself. She needs CG to provide her medication, daily needs, body and oral hygiene. She was refusing to use sanitary napkins when she got periods. Sometimes, she argues with her CG, made her furious and hit her. Her CG has a family and had expected baby for 2 months. She felt fully hand to keep her daily needs on tracks.

Extra oral examination showed butterfly rash on her facial presentation. Her angular lips were darker and moist. Intra oral examination showed erosive areas both on her lower and upper lips, bleed to labial mucosa, and also brown crustal in some spots on vermilion borders. Sloughing and erosive areas also found in buccal mucosa to retromolar pad and ventral tongue. Midline of hard palate and regio palatal of interdental gingiva had wide bleeding erosive areas. Gingival desquamation and bleeding found on buccal gingiva and vestibular mucosa. There are debris, plague, supra and subgingival calculus, radixes on 36 and 46coating and fissures on dorsal tongue. She had poor oral hygiene and

halitosis. She could only open her mouth up to three fingers, and there was spontaneous bleeding on her lips. (Figure 1)
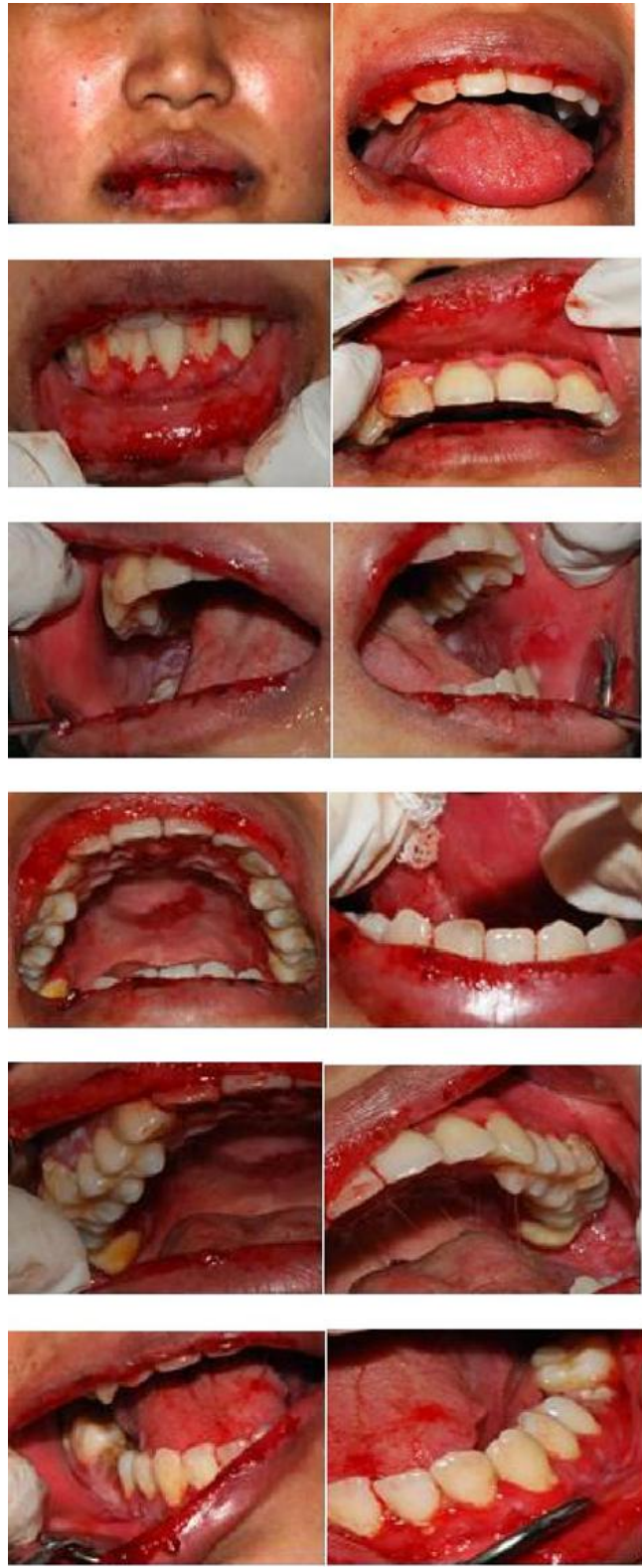

Figure 1. First Visit. Extra oral and intra oral presentation showed malar rash on both of her chins and spontaneous bleeding on her lips, hard palate and gingival interdental. Indentation also seen on both lateral tongue.

Laboratory's examination revealed hematology and immunology tests. The whole blood count and Anti Ds DNA was normal, the ANA test was negative. (Table 1)

Table 1. Laboratory's Examination

\begin{tabular}{ccc}
\hline Examination & Normal Value & First Visit \\
\hline Hemoglobin $(\mathbf{H b})$ & $11.5-16.5 \mathrm{~g} / \mathrm{dL}$ & 14.2 \\
Hematocrits $(\mathbf{H t})$ & $36-46 \%$ & 44.9
\end{tabular}




\begin{tabular}{|c|c|c|}
\hline Erythrocytes & $4.0-5.2 .10^{6} / \mu \mathrm{L}$ & 4.90 \\
\hline MCV & $80-100 \mathrm{fL}$ & 91.6 \\
\hline МCH & $26-34 \mathrm{pg}$ & 29.0 \\
\hline МСНС & $32-36 \mathrm{~g} / \mathrm{dL}$ & 31.6 \\
\hline Total & $150,000-$ & \\
\hline Thrombocyte & $450,000 / \mu \mathrm{L}$ & 314,000 \\
\hline Total Leukocyte & $4,400-11,300 / \mu \mathrm{L}$ & $12,570 \mathrm{H}$ \\
\hline Basophils & $0-1 \%$ & 0 \\
\hline Eosinophil & $2-4 \%$ & $0 \mathbf{L}$ \\
\hline Neutrophils & $50-70 \%$ & $86 \mathrm{H}$ \\
\hline Lymphocyte & $25-40 \%$ & $11 \mathrm{~L}$ \\
\hline Monocyte & $2-8 \%$ & 3 \\
\hline Bleeding time & $\begin{array}{c}0-25 \mathrm{~mm} / \text { hour } \\
\text { Negative:index }<1 .\end{array}$ & 20 \\
\hline ANA Test & $\begin{array}{c}0 \\
\text { Borderline:index } \\
\text { 1.0-1.2 } \\
\text { Positive:index }>1.2\end{array}$ & $\begin{array}{l}\text { Negative: } \\
\text { index } 0.2\end{array}$ \\
\hline Anti DNA Ds & $\begin{array}{c}\text { Normal: }<25 \mathrm{U} / \mathrm{mL} \\
\text { Elevated: } \geq 25 \\
\mathrm{U} / \mathrm{mL}\end{array}$ & 5.7 \\
\hline C3 Complement & $0-180 \mathrm{mg} / \mathrm{dL}$ & 107 \\
\hline C4 Complement & $10-40 \mathrm{mg} / \mathrm{dL}$ & 22.94 \\
\hline
\end{tabular}

The working diagnoses were oral manifestation of bullous lupus erythematosus, chronic gingivitis, radixes on 36 and 46. The Differential diagnosis was Pemphigus vulgaris, erythema multiform, and erosive lichen planus.

Communication, information, and education to the $\mathrm{CG}$ had been given to control patient's oral hygiene for helping her to brush her teeth twice a day, and instruction of her daily medication. She also has been instructed to do the one minute swish and rinse using Dexamethasone diluted with $10 \mathrm{ml}$ of water twice a day. The doses were 6 $\mathrm{mg}$ in the morning and $3 \mathrm{mg}$ in the afternoon and also usig lip ointment contains of $4 \mathrm{mg}$ Dexamethasone and Vaseline lanoline for the lips lesion twice a day. Elimination of focus infection had been suggested for scaling and extraction of radixes after her treatment had completed. The next visit scheduled after a week.

She was on schedule for her first visit and seems more cooperative than the first one. By the information given by the $\mathrm{CG}$, it was known that sometimes she skips brushing teeth and applying the lip ointment, unless the $\mathrm{CG}$ instructed her to do so. The Dexamethasone diluted water had been used as instructed. Sometimes she also use Chlorhexidine gluconate $0.2 \%$ to maintain her oral hygiene. Extra oral and intra oral presentation showed a better condition of oral hygiene, the bleeding reduced. Some erosive area on her lips, midline hard palate, buccal mucosa, retromolar pad, and gingival interdental became smaller and became healing. (Figure 2)
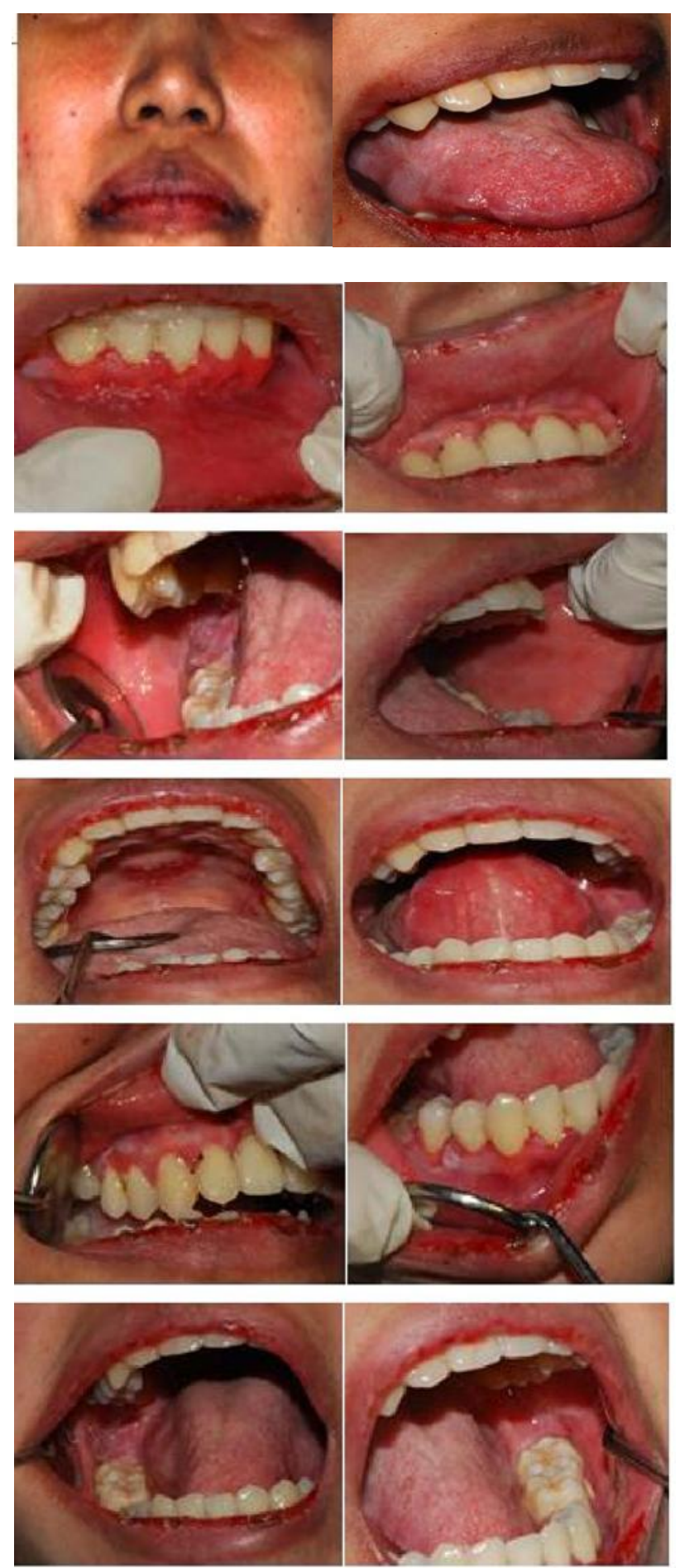

Figure 2. Fourth Visit. Extra oral and intra oral presentation showed better condition and moderate oral hygiene 
On her fourth visit four months later, her treatment of water diluted corticosteroid had been tapering down to 4 $\mathrm{mg}$ in the morning and $2 \mathrm{mg}$ in the afternoon. Her lip ointment changed to Clobetasol propionate $0.05 \%$ cream alternately with Vaseline album, twice a day.

Table 2. Laboratory's Examination

\begin{tabular}{|c|c|c|}
\hline Examination & Normal Value & Tenth Vis \\
\hline $\begin{array}{c}\text { Hemoglobin } \\
\text { (Hb) }\end{array}$ & $12.0-14.0 \mathrm{~g} / \mathrm{dL}$ & 12.8 \\
\hline $\begin{array}{l}\text { Hematocrits } \\
\text { (Ht) }\end{array}$ & $37.0-43.0 \%$ & 37.3 \\
\hline Erythrocytes & $4.0-5.0 .10^{6} / \mu \mathrm{L}$ & 4.43 \\
\hline MCV & $82-92 \mathrm{fL}$ & 84.2 \\
\hline МСН & $27.0-31.0 \mathrm{pg}$ & 28.9 \\
\hline МСHC & $32.0-36.0 \mathrm{~g} / \mathrm{dL}$ & 34.3 \\
\hline Total & $150,000-$ & \\
\hline Thrombocyte & $400,000 / \mu \mathrm{L}$ & 306,000 \\
\hline Total Leukocyte & $5,000-10,000 / \mu \mathrm{L}$ & 92,300 \\
\hline Basophils & $0-1 \%$ & 0.3 \\
\hline Eosinophil & $2-4 \%$ & $\mathbf{0} \mathbf{L}$ \\
\hline Neutrophils & $52-76 \%$ & $86.5 \mathrm{H}$ \\
\hline Lymphocyte & $20-40 \%$ & $10.9 \mathrm{~L}$ \\
\hline Monocyte & $2-8 \%$ & 2.3 \\
\hline Bleeding time & 0-20 mm/hour & $45 H$ \\
\hline C3 Complement & $90-180 \mathrm{mg} / \mathrm{dL}$ & 127.10 \\
\hline C4 Complement & $10-40 \mathrm{mg} / \mathrm{dL}$ & 29.0 \\
\hline
\end{tabular}

A month after her fourth visit, the CG gave birth and no one supervised the patient to do the medication as instructed. Considering her mental status, the medication was neglected neither the scheduled appointment. The oral lesion were flaring up, as well as the skin lesions. A single bulla was found on her right hand palm and her genital membrane.
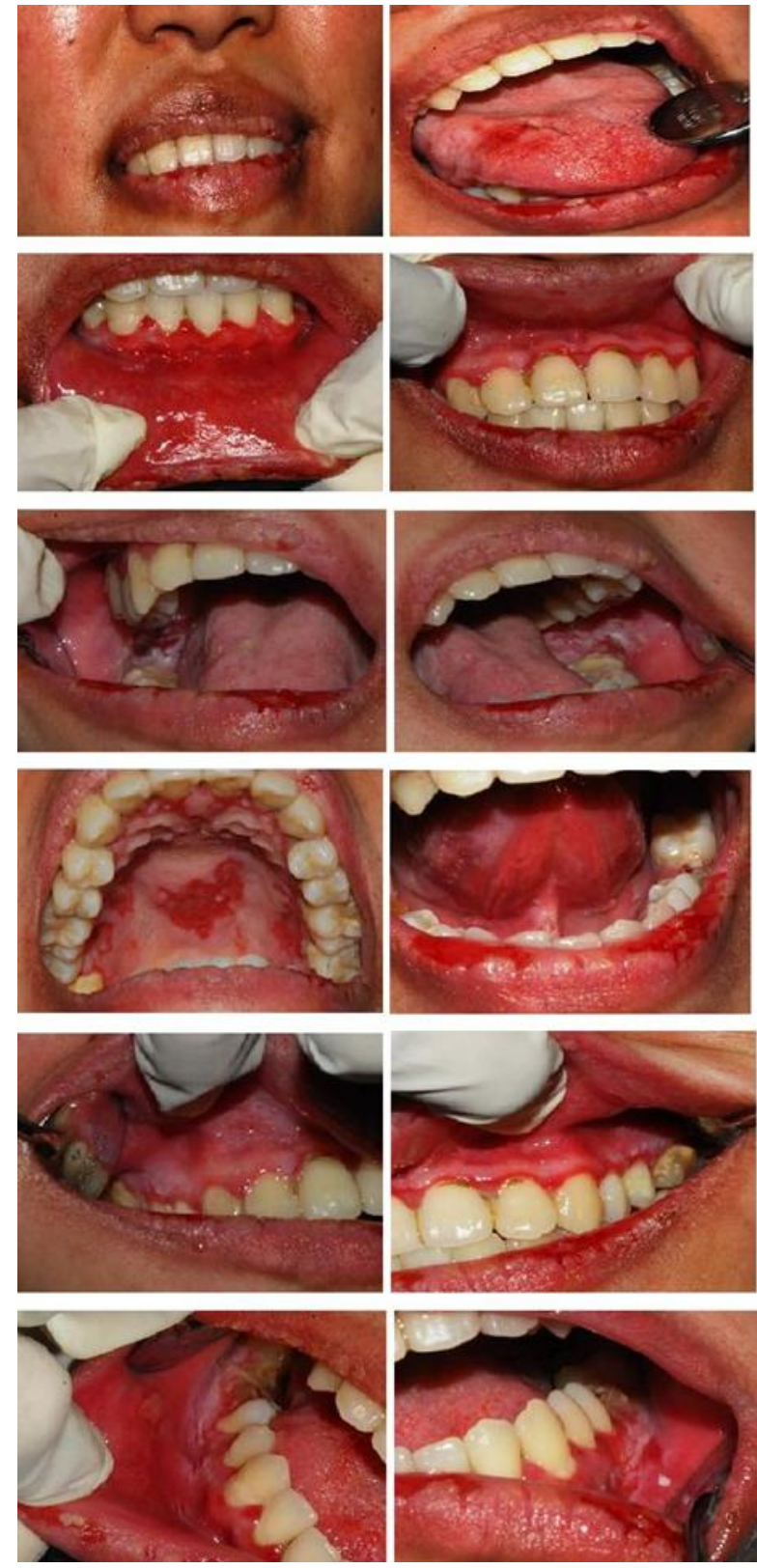

Figure 3. Tenth Visit. Her lesion became flaring up. There was sloughing on her dorsal tongue, lingual frenulum, ulcer on vestibular mucosa regio 46. Gingival desguamative on retromolar pad and buccal gingiva.

Table 3. TORCH Test

\begin{tabular}{|c|c|c|}
\hline Examination & Normal Value & Tenth Visit \\
\hline $\begin{array}{c}\text { Anti HSV I } \\
\text { IgG }\end{array}$ & $\leq 0.9$ nonreactive & $\begin{array}{c}\text { Reactive, index: } \\
6.89\end{array}$ \\
\hline $\begin{array}{c}\text { Anti HSV I } \\
\text { IgM }\end{array}$ & $\leq 0.9$ nonreactive & $\begin{array}{c}\text { Reactive, index: } \\
1.87\end{array}$ \\
\hline $\begin{array}{c}\text { Anti HSV II } \\
\text { IgG }\end{array}$ & $\leq 0.9$ nonreactive & $\begin{array}{c}\text { Nonreactive, index: } \\
0.19\end{array}$ \\
\hline
\end{tabular}




\section{Anti HSV II IgM \\ Nonreactive, index: 0.38}

The laboratory's examination revealed high value of neutrophils, prolonged bleeding time, low value of eosinophil and lymphocyte. The torch test showed herpes simplex virus (HSV) 1 infection. The patient was on 2 weeks treatment of Acyclovir from Dermatologist and her antimalarial treatment had been stopped. She had been instructed to compress the genital lesion using sterilized gauzes and saline. Her oral treatment of topical corticosteroid had been tapering up from to $6 \mathrm{mg}$ Dexamethasone in the morning, and $3 \mathrm{mg}$ in the afternoon. Alternately, she used swish and rinse saline twice a day. She still used clobetasol propionate $0.05 \%$ cream for her lip, alternately with Vaseline album twice a day. The importance of following a scheduled appointment was given to the CG despite of the CG full day activity taking care of her own baby. The agreement of one scheduled visit every two weeks was made. There is still ongoing treatment by the time this case report made.

\section{Discussion}

In this case report, skin lesions were the first present before oral lesions, but the CG said she hasn't have complaint in genital before. According to literature, it is difficult to ascertain the true incidence with which SLE presents with oral manifestations because of relative lack of symptoms and different referral pathways. Symptomatic patients may present early to dentists, oral surgeons or physicians, whereas asymptomatic patients may not present until much later when they develop cutaneous or systemic manifestations. ${ }^{5}$ Although the nasal conjunctive and genital mucosa may be involved. The oral mucosa is affected with greater frequency. ${ }^{6}$ However, clearly her oral treatment had been neglected for couple years.

The oral lesions are caused by vasculitis and appear as frank ulceration or mucosal inflammation. The intra oral mucosal lesions of LE most frequently affect the oral cavity and lips in the buccal mucosa are preferred sites, followed by the gums and palate. The lesions may be asymptomatic or painful and can coexist or even precede the skin lesions from LE. It should always be considered as a diagnosis in patients with oral lesions, thus early diagnosis of the disease and referral to specialized centers is essential. ${ }^{6,7}$ It is consisted to the patient conditions of the oral lesion. Erosive area on her lips and buccal mucosa to retromolar pad not only site of the lesion, but also on midline hard palate and labial gingiva, in fact almost of her oral mucosa sites had lesion. She didn't feel pain all the time, it might be because her lacking communication with other people.

The prevalence of oral lesions in patients with SLE is variable and might depend on the state of the disease and the treatment received. Oral manifestations of LE do not

represent a constant finding and may vary from the systemic to the cutaneous pole. In our study, the major percentage of oral lesions was found in SLE consistent with previous works. High prevalence of oral lesions in SLE is probably because of the fact that all tissues are potentially affected in this pole of the disease. ${ }^{2}$

The oral lesions in acute LE are very common and appear erythematous stains of purple color with desquamative gingivitis, palatal erythema, and rarely ulcers. The bullae appear associated with bullous LE and affect the lip in a linear fashion. The palate and buccal mucosae are often ulcerated. These are less painful; however, there are reports of chronic pain and chronic burning. ${ }^{8}$

Clinically, the lesions of oral SLE are asymptomatic ulcerations that most often resemble erosive lichen planus. Other oral manifestations of SLE may include secondary infection of ulcerative lesions with candidiasis, and the presence of ecchymosis, petechiae, and bleeding. The bleeding manifestations are associated with autoimmune hemolytic anemia or thrombocytopenia. ${ }^{9}$

The most important diagnostic laboratory test for SLE is the test for antinuclear antibody (ANA) in the serum, which is positive for $96-100 \%$ of patients. More than $90 \%$ of patients with SLE show granular deposition of complement fractions, usually C3 and immunoglobulin's at the basement membrane zone (lupus band test). ${ }^{5}$

Bullous systemic lupus erythematosus (BSLE) is an autoantibody-mediated disease with subepidermal blisters. It is a rare presentation of SLE occurring in less than $5 \%$ of lupus cases. Clinically, BSLE presents as tense bullous lesions that can be serous or hemorrhagic and spread rapidly to all parts of the body, although lesions are mainly found on the trunk and in sun-exposed areas; they can also affect mucous membranes. The clinical manifestations of BSLE are characterized by vesicles, serous blisters, or hemorrhagic content in the face, neck, and trunk. Lesions can be located in areas both exposed and unexposed to the sun. They may be accompanied by mild to severe itching and can affect mucous membranes. BSLE lesions may heal completely, or result in hypo-or hyperpigmentation or scarring. ${ }^{10-12}$ The differential diagnosis depends on the lesion morphology, for Bullous LE: PV, MMP, simplex herpes, varicella, and erythema multiforme. ${ }^{6}$

Treatment of SLE is multi-factorial and includes education, such as avoidance of ultraviolet light, general management of infections, cardiovascular risk factors and treatment complications including osteoporosis, in combination with pharmacological therapies tailored to the individual's disease. Steroids and antimalarials are the standard treatments for the cutaneous manifestations of SLE. ${ }^{13,14}$

Slightly brownish pigmentation has been described in oral mucosa of patients with SLE receiving antimalarials. Oral lesions were found in patients with less than 2 years of diagnosis. Immunosuppressive treatments probably 
maintain patients free of mucosal alterations. ${ }^{2}$

Dentists must enforce preventive dental care and monitor patients with SLE closely for head and neck infections because they are predisposed to severe infections. Thorough clinical examination is required to avoid overlooking infections. Infections can progress rapidly in patients with SLE because of disease or therapy-related immunosuppression. A multidisciplinary approach to medical consultation and appropriate referrals ensures comprehensive medical and dental management of patients with SLE. For patients with SLE, emphasis is therefore placed on the dental team's continuous reinforcement of good oral hygiene, provision of close monitoring for and aggressive treatment of dental and oral infections, and assistance with the diagnosis of mucocutaneous lesions of the head and neck. ${ }^{8,10,15}$

\section{Conclusion}

In summary, effective communication, information, and education to caregiver are very important in the management of SLE patient with mental retardation. Establishment of trust and equality goals of care is important to overcome the limitations of communication and patient compliance in this case.

\section{Acknowledgement}

My gratitude for Cipto Mangunkusumo Hospital for the collaboration and Dr. drg. Harum Sasanti, Sp.PM, drg. Endah Tri Wulandari, Sp.PM, drg. Indriasti Indah Wardhany, Sp.PM, drg. Afi Savitri, SpPM, drg. Ahmad Ronal, SpPM, and drg. Anandina Irmagita, Sp.PM as a supervisor in evaluating the patient.

\section{References}

1. Gottlieb B, Ilowite N. Systemic lupus erythematosus in children and adolescents. Pediatr Rev. 2006;59(2):345-364. doi:10.1016/j.pcl.2012.03.007.Systemic.

2. Loez-Labady J, Villarroel-Dorrego M, Gonzaíez N, Peez R, Mata De Henning M. Oral manifestations of systemic and cutaneous lupus erythematosus in a Venezuelan population. J Oral Pathol Med. 2007;36:524-527. doi:10.1111/j.16000714.2007.00569.x.

3. Guillermo J. Pons-Estel, Alarcón GS, Scofield L, Reinlib L, Cooper GS. Understanding the Epidemiology and Progression Systemic Lupus Erythematosus. NIH Public Access. 2010;39(4):1-23. doi:10.1016/j.semarthrit.2008.10.007.Understanding.

4. Jolly M, Thakkar A, Mikolaitis RA, Block JA. Caregiving, dyadic quality of life and dyadic relationships in lupus. Lupus. 2015;24(9):918-926. doi:10.1177/0961203314567749.

5. Ramakrishna Y, Reddy JS. Systemic lupus erythematosus presenting with oral mucosal lesions--a case report. J Clin Pediatr Dent. 2009;33(3):255-258. http://www.ncbi.nlm.nih.gov/pubmed/19476102.

6. Ramos-e-Silva M, Ferreira A, de-Moura-Castro Jacques C. Oral involvement in autoimmune bullous diseases. Clin Dermatol. 2011;29(4):443-454. doi:10.1016/j.clindermatol.2011.01.015.

7. Mina R, Brunner HI. Update on differences between childhood-onset and adult-onset systemic lupus erythematosus. Arthritis Res Ther. 2013;15(4):218. doi:10.1186/ar4256.

8. Albilia JB, Lam DK, Clokie CML, Sándor GKB. Systemic Lupus Erythematosus: A Review for

Dentists. J Can Dent Assoc. 2010;111(3):665-676. doi:10.1213/ANE.0b013e3181e8138e.

9. Gurenllan JR. Systemic Lupus erythematosus. Lupus. 1994;(October):50-54

10. Wang G, Wang C, Xu X, Jia H. Two cases of bullous systemic lupus erythematosus treated successfully with T2 and low-dose corticosteroids. DermatologicaSin.

2015:8-11 doi:10.1016/j.dsi.2015.08.004

11. Duan L, Chen L, Zhong S, et al. Treatment of Bullous Systemic Lupus Erythematosus. J Immunol Res. 2015;2015. doi:10.1155/2015/167064.

12.Vassileva S. Bullous systemic lupus erythematosus. Clin Dermatol. 2000;22(2):129138.doi:10.1016/j.clindermatol.2003.12.020.

13. Kole AK, Ghosh A. Cutaneous manifestations of systemic lupus erythematosus in a tertiary referral center. Indian J Dermatol. 2009;54(2):132-136. doi:10.4103/0019-5154.53189.

14. Seo JY, Byun HJ, Cho KH, Lee EB. Methimazoleinduced bullous systemic lupus erythematosus: A case report. J Korean Med Sci. 2012;27(7):818-821. doi:10.3346/jkms.2012.27.7.818.

4. Beusterien K, Bell J, Grinspan J, Utset T, Kan H, Narayanan S. Physician-patient interactions and outcomes in systemic lupus erythematosus (SLE): a conceptual model. Lupus. 2013;22:1038-1045. doi:10.1177/0961203313499958. 